\title{
Coal Fly Ash Characterization from Cement Industry " $X$ " as an Initial Study in Its Utilization
}

\section{Karakterisasi Abu Batubara Industri Semen "X” sebagai Studi Awal untuk Pemanfataannya}

\author{
Farrah Fadhillah Hanum ${ }^{\mathrm{a}, 1, *}$, Aster Rahayu a,2, Ulung Muhammad Sutopo ${ }^{\mathrm{b}, 3}$, Zahrul Mufrodi ${ }^{\mathrm{a}, 3}$ \\ ${ }^{a}$ Universitas Ahmad Dahlan, Jl. Ringroad Selatan, Kragilan, Tamanan, Bantul, D. I. Yogyakarta, 55191

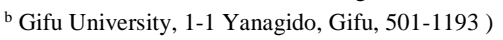 \\ ${ }^{1}$ farrah.hanum@che.uad.ac.id*; ${ }^{2}$ aster.rahayu@che.uad.ac.id; ${ }^{3}$ ulung_msutopo@yahoo.com, ${ }^{4}$ zahrul.mufrodi@che.uad.ac.id \\ * corresponding author
}

\section{ARTICLE INFO}

Article history

Received May 17, 2020

Revised June 08, 2020

Accepted June 18, 2020

\section{Keywords}

Characterization

Coal fly ash

XRF

SEM

Environment

\section{ABSTRACT}

The discharge of fly ash from the coal combustion process has become a matter of concern over the last few decades. Most of the fly ash will be disposed of in the landfill. This disposal gives a negative impact on the environment through the heavy metal contained in fly ash. Coal fly ash characterization is needed to be done to get proper information about coal fly ash before it could be utilized. In this research, coal fly ash characterization from one of cement industry in Indonesia has been done by a qualitative and quantitative method. This research carried out some instrumentation such as Scanning Electron Microscopy (SEM), X-ray fluorescence spectrometer (XRF) and SEM - Electron Dispersive X-ray spectroscopy (SEM-EDX) to analyze the coal fly ash sample. The result showed that the main component in this coal ash sample is $\mathrm{SiO}_{2}, \mathrm{Al}_{2} \mathrm{O}_{3}, \mathrm{Fe}_{2} \mathrm{O}_{3}, \mathrm{CaO}$, and $\mathrm{MgO}$. This information will be used as an initial study in coal fly ashes utilization research in the next research.

\section{Pendahuluan}

Indonesia merupakan negara dengan cadangan batubara yang cukup melimpah di dunia dengan total cadangan batubara Indonesia adalah 22,6 miliar ton atau 2,2 persen dari total cadangan global. Kondisi ini mendorong pemerintah untuk menetapkan kebijakan untuk meningkatkan penggunaan batubara sebagai bahan baku untuk pembangkit tenaga listrik. Lebih dari $88 \%$ dari listrik yang dihasilkan berasal dari $60 \%$ dari batu bara, $22 \%$ dari gas alam, dan $6 \%$ dari minyak dan $12 \%$ nya dari energi terbarukan [1].

Selain pada PLTU, batubara juga digunakan sebagai bahan bakar di berbagai industri salah satunya adalah industri semen. Kondisi ini menimbulkan permasalahan lingkungan salah satunya ialah abu sisa dari proses pembakaran batu bara baik itu fly ash atau bottom ash.

Pada penelitian ini penulis fokus pada karakterisasi dari abu batubara yang dihasilkan oleh Pabrik Semen X. Dengan tujuan utama yaitu untuk mendapatkan informasi awal yang dapat menunjang riset penulis dalam riset lanjutannya yaitu pemanfataan abu batubara (fly ash). Fly ash merupakan padatan sisa pembakaran batubara yang terbawa oleh gas buang dan ditangkap oleh alat pengendali udara. Hampir $80 \%$ dari total abu batu bara merupakan fly ash yang memiliki butiran sangat halus (sekitar 200 mesh) yang sangat berpotensi menimbulkan pencemaran lingkungan [2]. 
Berdasarkan peraturan pemerintah No. 85 tahun 1999 dan Peraturan Pemerintah No. 18 Tahun 1999 tentang Pengelolaan Limbah Bahan Berbahaya dan Beracun, abu batubara diklasifikasikan sebagai limbah bahan berbahaya dan beracun (B3) karena memiliki kandungan logam berat, sehingga penggunaannya harus sesuai dengan ketentuan tersebut [3].

Di sisi lain, juga telah diketahui bahwa abu batubara telah banyak dimanfaatkan dalam berbagai macam penggunaan. Pemanfataan yang paling umum di Indonesia saat ini adalah sebagai bahan aditif pada industri semen, bahan aditif dalam pembuatan batako (building materials), timbunan jalan (road and pavement construction), soil amandement dan lain sebagainya. [4,5]. Namun, tidak semua jenis abu batubara yang dihasilkan dari proses pembakaran dapat memenuhi kriteria untuk pemanfaatan tersebut. Oleh karena itu, perlu diketahui karakterisasi dari jenis abu batubara yang dihasilkan suatu industri sebelum dapat dibahas lebih lanjut pemanfataannya. Contohnya, dari karakterisasi secara kualitatif dan kuantitatif akan dapat diketahui unsur dan senyawa yang terkandung pada sampel fly ash, dari informasi tersebut akan dapat diketahui apakah sampel fly ash ini akan dapat dimanfaatkan menjadi media tanam, diekstrak logamnya untuk dimanfaatkan kembali sebagai bahan baku suatu produk lain, kemungkinan menghasilkan nanosilika, dan lain sebagainya [6-9].

Metode karakterisasi yang digunakan dalam studi ini meliputi metode kualitatif dan kuantitatif dengan analisis sampel menggunakan beberapa instrumentasi umum yaitu Scanning Electron Microscopy (SEM) untuk metode kualitatif dan analisis dengan $X$-ray fluorescence spectrometer (XRF) dan SEM - Electron Dispersive X-ray spectroscopy (SEM-EDX) untuk metode kuantitatif. Scanning Electron Microscopy (SEM) adalah mikroskop electron yang digunakan untuk menyelidiki permukaan objek solid secara langsung. Dan SEM-EDX merupakan jenis dari SEM yang dapat memungkinkan dilakukannya mikroanalisis secara kualitatif dan semi kuantitatif untuk unsur-unsur [10-11]. Dan X-ray fluorescence spectrometer (XRF) adalah merupakan sebuah spektometer yang dapat digunakan untuk pengujian secara kualitatif dan kuantitatif. Teknik ini merupakan suatu teknik analisis untuk mengetahui unsur dan senyawa yang membangun suatu material dan kemudian menghitung konsentrasi dari unsur dan senyawa tersebut berdasarkan panjang gelombang dan sinar X yang dpancarkan [12-13].

Dalam makalah ini diuraikan analisis dan karakterisasi dari sampel yang diharapkan dapat memberikan informasi untuk studi lanjutan mengenai pemanfataan dari abu batubara sebagai salah satu solusi untuk mengurangi dampak polusi akibat buangan abu batubara di lingkungan.

\section{Metodologi}

\subsection{Alat dan Bahan}

Pada studi ini peneliti akan melalukan karakterisasi terhadap sampel abu batubara dari proses pembakaran salah satu pabrik semen di Indonesia. Pada pembahasan akan dituliskan dengan Industri Semen X. Karakterisasi terhadap sampel abu batubara ini dilakukan dengan menyimpulkan hasil dari tiga jenis alat instrument yaitu X-ray fluorescence spectrometer (XRF; WDXRF S8 TIGER, Bruker AXS), Scanning Electron Microspocy (SEM; HITACHI, TM4000Plus, Miniscope), dan SEM - Electron Dispersive X-ray spectroscopy (SEM-EDX; HITACHI, SU3500).

\subsection{Metode}

Karakterisasi terhadap sampel abu batubara dilakukan secara kualitatif dan kuantitatif dengan menggunakan dua teknik analisis yaitu Scanning Electron Microspocy (SEM) dan X-ray fluorescence spectrometer (XRF). Analisis dengan Scanning Electron Microspocy (SEM) dan SEM - Electron Dispersive X-ray spectroscopy (SEM-EDX) untuk mengetahui jenis unsur yang terkandung di dalam sampel juga dapat menampilkan bentuk morfologi dari sampel pada variasi perbesaran 1000, 3000, dan 5000 kali. Sampel abu batubara yang telah dipersiapkan diinputkan pada alat SEM dan SEM-EDX, kemudian akan dianalisis dengan menggunakan tegangan sebesar $15 \mathrm{kV}$ dengan deep of field 7,2 $\mathrm{mm}$.

Selain itu, dilakukan juga pengujian kuantitatif dengan menggunakan $X$-ray fluorescence spectrometer (XRF). Analisis dengan XRF ini digunakan untuk mendapatkan informasi jumlah 
kandungan senyawa-senyawa dalam sampel abu batubara. Senyawa yang dapat diketahui pada sampel ini adalah berupa senyawa oksida karena abu batubara merupakan hasil dari proses pembakaran dengan suhu tinggi. Senyawa tersebut antara lain adalah $\mathrm{SiO}_{2}, \mathrm{Fe}_{2} \mathrm{O}_{3}, \mathrm{Al}_{2} \mathrm{O}_{3}, \mathrm{CaO}, \mathrm{MgO}$ dan beberapa komponen pelengkapnya seperti $\mathrm{K}_{2} \mathrm{O}, \mathrm{P}_{2} \mathrm{O}_{5}, \mathrm{SO}_{3}$, dan lain sebagainya.

Metode-metode yang digunakan ini memberikan cukup informasi mengenai unsur dan senyawa yang terkandung di dalam sampel fly ash. Informasi ini sangat diperlukan sebagai informasi awal dalam memilih alternatif pemanfaatan sampel abu batubara ini nantinya.

\section{Hasil dan Pembahasan}

Makalah ini merupakan studi awal terhadap abu batubara untuk mengetahui karakteristik dari abu batubara sisa hasil pembakaran Industri Semen X dengan menampilkan data secara kualitatif dan kuantitatif.

\subsection{Analisis Kualitatif dengan Metode Scanning Electron Microscopy (SEM)}

Analisis identifikasi morfologi permukaan terhadap sampel abu batubara ini diamati pada tiga variasi nilai perbesaran yaitu 1000, 3000, dan 5000 kali yang dapat dilihat pada Gambar 1 - Gambar 3 berikut.

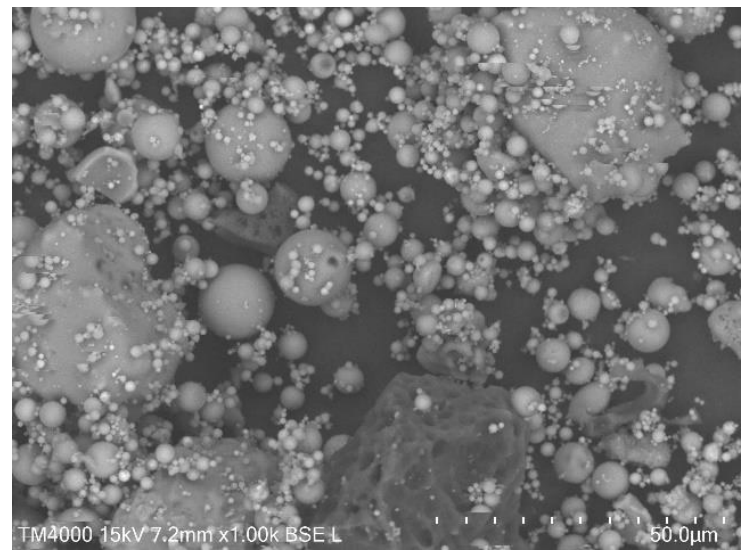

Gambar 1. Foto Scanning Electron Microscopy (SEM) pada nilai perbesaran 1000 kali

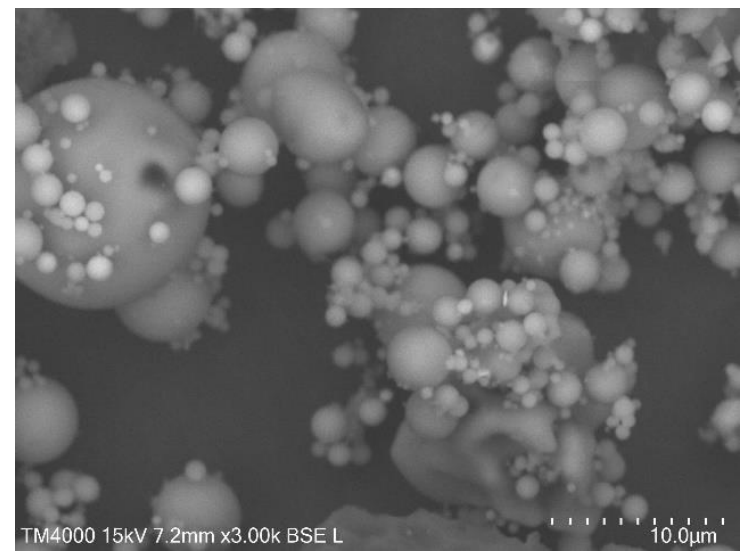

Gambar 2. Foto Scanning Electron Microscopy (SEM) pada nilai perbesaran 3000 kali 


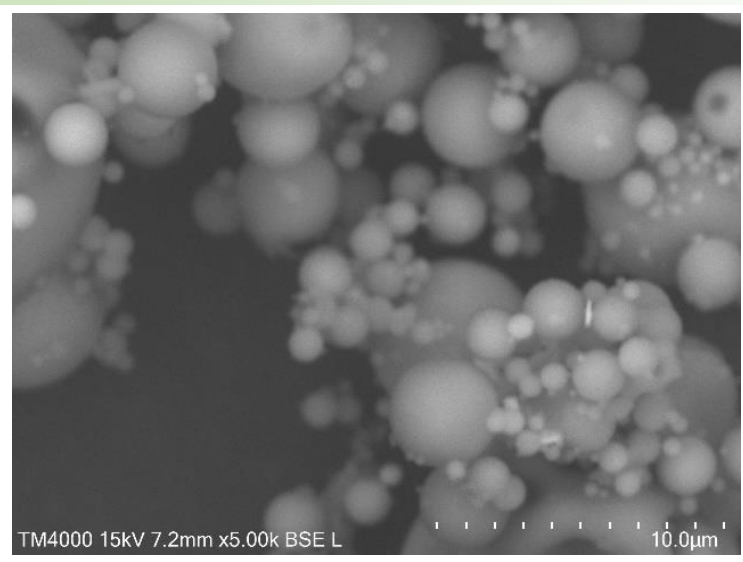

Gambar 3. Foto Scanning Electron Microscopy (SEM) pada nilai perbesaran 5000 kali

Morfologi permukaan dari sampel abu batubara dari Industri Semen X dapat dilihat pada tiga variasi perbesaran seperti pada gambar-gambar di atas. Hasil Scanning Electron Microscopy (SEM) menunjukkan bentuk strukturnya adalah spherical yang beraturan, juga semakin gambar diperbesar maka akan semakin terlihat dengan jelas terdapat aglomerasi di beberapa titik. Ukuran dari strukturstruktur komponen utama ini pun bervariasi, yaitu antara 1,18 $\mu \mathrm{m}$ sampai dengan $912 \mathrm{~nm}$, yang dapat dilihat pada Gambar. 4 berikut:

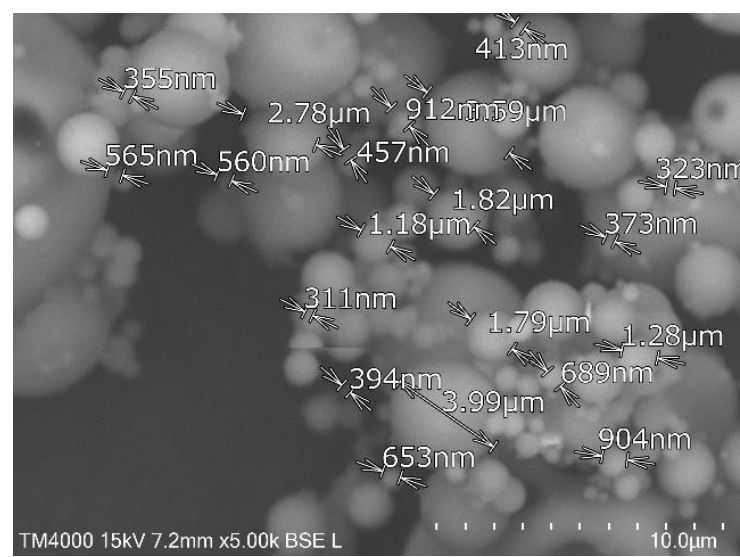

Gambar 4. Foto Scanning Electron Microscopy (SEM) pada nilai perbesaran 5000 kali dengan ukuran size komponen utamanya

\subsection{Analisis Kuantitatif dengan metode XRF dan SEM-EDX}

Metode x-ray fluorescence spectrometer (XRF) dan SEM - Electron Dispersive X-ray spectroscopy (SEM-EDX) sama-sama menunjukkan hasil kuantitatif dari komponen-komponen penyusun dari sampel. Pada metode $x$-ray fluorescence spectrometer (XRF) didapatkan hasil dalam bentuk persentase dari senyawa oksida dari komponen penyusun utamanya dan pada metode SEM Electron Dispersive X-ray spectroscopy (SEM-EDX) didapatkan hasil dalam bentuk persentase massa dari unsur-unsur penyusunnya.

Tabel 1 menunjukkan komponen utama hasil analisis dengan metode $x$-ray fluorescence spectrometer (XRF). Diketahui seperti abu batubara pada umumnya silika dalam bentuk $\mathrm{SiO}_{2}$ merupakan komponen penyusun utamanya. Namun jumlah ini relatif lebih kecil dibandingkan jenis sampel abu batubara yang dihasilkan oleh pembangkit listrik tenaga seperti yang pernah penulis bahas pada makalah-makalah sebelumnya [14-15]. Selain itu, jika dibandingkan dengan hasil pada penelitian sebelumnya tersebut, persentase jumlah dari komponen-komponen penting seperti $\mathrm{Fe}_{2} \mathrm{O}_{3}$, $\mathrm{CaO}$ dan $\mathrm{MgO}$ jauh lebih tinggi jika dibandingkan dengan sampel-sampel abu batubara pada 
peelitian sebelumnya. Hal ini menunjukkan bahwa perbedaan karakterisasi dari komponenkomponen ini dapat memberikan hasil yang berbeda pula pada nantinya pada pemanfaatannya.

Tabel 1. Komposisi Kimia Abu Batubara Industri Semen X metode XRF

\begin{tabular}{cc}
\hline Komponen & $($ \% m) \\
\hline $\mathrm{SiO}_{2}$ & 45,38 \\
$\mathrm{Al}_{2} \mathrm{O}_{3}$ & 21,4 \\
$\mathrm{TiO}_{2}$ & 0,91 \\
$\mathrm{Fe}_{2} \mathrm{O}_{3}$ & 14,05 \\
$\mathrm{CaO}$ & 9,52 \\
$\mathrm{MgO}$ & 5,18 \\
$\mathrm{Na} 2$ & 1,62 \\
$\mathrm{~K}_{2} \mathrm{O}$ & 0,91 \\
$\mathrm{P}_{2} \mathrm{O}_{5}$ & 0,11 \\
$\mathrm{MnO}_{2}$ & 0,06 \\
$\mathrm{~V}_{2} \mathrm{O}_{5}$ & 0,02 \\
$\mathrm{SO}_{3}$ & 0,89 \\
\hline Total & $\mathbf{1 0 0 , 0 0}$ \\
\hline
\end{tabular}

Hasil Tabel 1 juga didukung oleh hasil analisis dari SEM - Electron Dispersive X-ray spectroscopy (SEM-EDX) pada Tabel 2. Di sini dapat dilihat Si dan Al merupakan unsur merupakan utama yang terkandung dalam sampel abu batubara ini. Oksigen (O) tentunya akan memiliki persentase massa yang paling besar $(44,66 \%)$ karena hasil proses pembakaran akan selalu dalam bentuk oksida yang artinya memiliki kandungan oksigen. Dapat diketahui bahwa unsur-unsur utama yang terdapat ada sampel abu batubara ini adalah Si dan Al dengan masing-masing 24,2 dan 22,84 persen massa. Kemudian diikuti dengan $\mathrm{Na}(2,73 \%), \mathrm{K}(1,15 \%), \mathrm{Zr}(1,27 \%), \mathrm{Cu}(0,82 \%), \mathrm{Fe}$ $(0,59 \%)$, dan $\mathrm{Ca}(0,36 \%)$. Hal ini juga terlihat pada grafik dari SEM-EDX yang terdapat pada Gambar 5.

Tabel 2. Komposisi Kimia Abu Batubara Industri Semen X metode SEM-EDX

\begin{tabular}{cc}
\hline Komponen & $\mathbf{( \% ) ~ m ) ~}$ \\
\hline $\mathrm{N}$ & 0.45 \\
$\mathrm{O}$ & 44.66 \\
$\mathrm{Na}$ & 2.73 \\
$\mathrm{Mg}$ & 0.21 \\
$\mathrm{Al}$ & 22.84 \\
$\mathrm{Si}$ & 24.2 \\
$\mathrm{P}$ & 0 \\
$\mathrm{~S}$ & 0.46 \\
$\mathrm{Cl}$ & 0 \\
$\mathrm{~K}$ & 1.15 \\
$\mathrm{Ca}$ & 0.36 \\
$\mathrm{Mn}$ & 0.17 \\
$\mathrm{Fe}$ & 0.59 \\
$\mathrm{Cu}$ & 0.82 \\
$\mathrm{Zn}$ & 0 \\
$\mathrm{As}$ & 0 \\
$\mathrm{Zr}$ & 1.27 \\
$\mathrm{Cs}$ & 0.08 \\
\hline Total & $\mathbf{1 0 0}$ \\
\hline
\end{tabular}

\section{Kesimpulan}

Dari pembahasan hasil analisis sampel abu batubara dari Industri Semen X secara kualitatif dan kuantitatif dapat diketahui bahwa terdapat perbedaan karakter pada setiap abu batubara (fly ash), yang tentunya akan dapat memberikan karakter yang berbeda pada saat pemanfaatannya nanti. Komposisi penyusun utama dari sampel abu batubara ini adalah $\mathrm{SiO}_{2}, \mathrm{Al}_{2} \mathrm{O}_{3}, \mathrm{Fe}_{2} \mathrm{O}_{3}, \mathrm{CaO}$ dan $\mathrm{MgO}$. Informasi pada makalah ini akan sangat membantu dalam memberi arahan metode penanganan fly ash untuk mengurangi dampak terhadap lingkungan hidup. 


\section{Ucapan Terima Kasih}

Kami ingin mengucapkan terima kasih kepada Prof. Shinji Kambara (Environmental and Renewable Energy System Division) dan Prof. Fusheng Li (River Basin Research Center) dari Faculty of Engineering, Gifu University, Jepang yang memfasilitasi terlaksanannya penelitian ini.

\section{Daftar Pustaka}

[1] D. Arinaldo., J. C. Adiatma., "Dinamika Batu Bara Indonesia: Menuju Transisi Energi yang Adil", Jakarta: Institute for Essential Services Reform (IESR), 2019.

[2] M. Munir., "Pemanfaatan Abu Batubara (Fly Ash) untuk Hollow Block yang Bermutu dan Aman Bagi Lingkungan", Semarang: Program Pascasarjana Universitas Diponegoro, 2008.

[3] E. Wardani., M. Sutisna., A. H. Dewi., "Evaluasi Pemanfaatan Abu Terbang (Fly Ash) Batubara Sebagai Campuran Media Tanam Pada Tomat”, Bandung: Institut Teknologi Nasional, 2012.

[4] A. R. Kurniawan,. D. D. Adenan., S. R. Untung., N.R. Hadijah., M. Alimano., "Penelitian Pemanfaatan Abu Batubara PLTU Untuk Penimbunan Pada Pra Reklamasi Tambang Batubara", Bandung: Puslitbang Teknologi Mineral dan Batubara Badan Litbang Energi dan Sumber Daya Mineral, 2010.

[5] R. Damayanti., "Abu Batubara Dan Pemanfaatannya: Tinjauan Teknis Karakteristik Secara Kimia Dan Toksikologinya", Bandung: Jurnal Teknologi Mineral dan Batubara, 2018.

[6] A. Rahayu., J. A. Fajri., L. W. Lim., T. Takeuchi., "Pembuatan Kolom Monolit Mixed-Mode untuk Pemisahan Fenol dalam Kromatografi Cair Sistem Kapiler", Yogyakarta: Chemica. Vol. 5, No. 2, pp 43-50, 2018.

[7] R. N. Sari., Nurhasni., M A. Yaqin., "Sintesis Nanopartikel ZNO Ekstrak Sargassum sp. dan Karakteristik Produknya”, Jurnal Pengolahan Hasil Perikanan Indonesia”, 20(2):238-254, 2017.

[8] I. Desianti., Rahmaniah., S. Zelviani., "Karakterisasi Nanosilika Dari Abu Terbang (Fly Ash) Pt. Bosowa Energi Jeneponto Dengan Menggunakan Metode Ultrasonic", JFT.No. 2, Vol. 5, Desember, 2018.

[9] D. A. Chaidir., H. Kristanto., A. Andreas., "Synthesis of Nanosilica Originated from Fly Ash using SolGel Method with Methanol as Solvent", Prosiding Seminar Nasional Teknik Kimia "Kejuangan", ISSN 1693-4393, 2016.

[10] Administrator UPT LTSIT. "Scanning Electron Microscope (SEM-EDX)” UPT LTSIT, Oktober, 2016.

[11] A. Sujatno., R. Salam., Bandriyana., A. Dimyati., "Studi Scanning Electron Microscopy (Sem) Untuk Karakterisasi Proses Oxidasi Paduan Zirkonium”, JFN, Volume 9, Nomor 2, 2015.

[12] M. Munasir., T. Triwikantoro., M Zainuri, D. Darminto., "Uji XRD dan XRF pada Bahan Meneral (Batuan dan Pasir) Sebagai Sumber Material Cerdas $\left(\mathrm{CaCO}_{3}\right.$ dan $\left.\mathrm{SiO}_{2}\right)$ ”, JPFA, Vol 2, No. 1, Juni 2012.

[13] A. Jamaludin., D. Adiantoro., “Analisis Kerusakan X-Ray Fluoresence (XRF)”, BATAN, No. 09 - 10 / Tahun V, April - Oktober, 2012.

[14] F. F. Hanum., E. D. Desfitri. S. Kambara., "Advanced study on additives for controlling As, Se, B and F leaching concentration from coal fly ash”, Proceeding: Japan Institute of Energy, 2018.

[15] F. F. Hanum., E. D. Desfitri., Y. Hayakawa., S. Kambara., "The role of calcium compound on fluorine leaching concentration", IOP conference Series: Materials Science and Engineering, 2019. 